\title{
Article
}

\section{A Small-Scale Concept-based Laboratory Component: The Best of Both Worlds}

\section{Dina Gould Halme, ${ }^{*+}$ Julia Khodor, ${ }^{* \dagger}$ Rudolph Mitchell, ${ }^{\ddagger}$ and Graham C. Walker}

\author{
*Department of Biology and the ${ }^{\ddagger}$ Teaching and Learning Laboratory, Massachusetts Institute of Technology, \\ Cambridge, MA 02139-4307
}

Submitted February 22, 2005; Accepted October 27, 2005

Monitoring Editor: Julio F. Turrens

\begin{abstract}
In this article, we describe an exploratory study of a small-scale, concept-driven, voluntary laboratory component of Introductory Biology at the Massachusetts Institute of Technology. We wished to investigate whether students' attitudes toward biology and their understanding of basic biological principles would improve through concept-based learning in a laboratory environment. With these goals in mind, and using our Biology Concept Framework as a guide, we designed laboratory exercises to connect topics from the lecture portion of the course and highlight key concepts. We also strove to make abstract concepts tangible, encourage learning in nonlecture format, expose the students to scientific method in action, and convey the excitement of performing experiments. Our initial small-scale assessments indicate participation in the laboratory component, which featured both hands-on and minds-on components, improved student learning and retention of basic biological concepts. Further investigation will focus on improving the balance between the minds-on concept-based learning and the hands-on experimental component of the laboratory.
\end{abstract}

\section{INTRODUCTION}

\section{Motivation for a Small-Scale, Concept-based Laboratory Component}

A number of educators and researchers have demonstrated the advantages of small learning environments for student progress (Cotton, 2000; Holland, 2002; Jobs for the Future, Kellogg Foundation, 2002; American Institutes for Research, 2003). However, in many institutions, large lecture courses are a financial and logistical necessity. For example, at the Massachusetts Institute of Technology (MIT), where Introductory Biology is a graduation requirement for all students, three educationally equivalent Introductory Biology courses serve approximately 900 students each academic year. Although these students attend lectures ranging from 100 to 400 students, they also meet in recitation sections ranging from 10 to 25 students. In this article, we argue that such small learning environments can be effectively used if they involve aspects of both minds-on and hands-on learning.

DOI: $10.1187 /$ cbe. $05-02-0065$

${ }^{+}$These authors contributed equally to this work.

Address correspondence to: Graham C. Walker (gwalker@mit.edu).
One of the major goals of the MIT courses, as of any Introductory Biology class, is to create enduring understanding of key biological principles. We aim to provide students with the tools with which to approach questions related to biology that they may face as members of society. Unfortunately, this goal is hard to achieve in a fast-paced Introductory Biology course that requires students both to learn many new concepts and to understand the approaches and findings of several different scientific disciplines. While it is clear to an expert that all the topics in the course are connected, novice students often see the course as consisting of "separate units." As a consequence, they feel that each unit, once finished, can be forgotten with no detriment to their understanding of the material in any other unit. If they fail to grasp the interconnectivity of the various units, students often resort to memorizing the details of a particular topic and thus gain a poorer understanding of the fundamental principles of biology.

As part of an effort to overcome the disjointedness and emphasis on detail that many students perceive in Introductory Biology courses, we have taken the approach of organizing the concepts and details covered in the courses taught at our institution into a Biology Concept Framework (BCF; 
Khodor et al., 2004). Our BCF is hierarchical, places details in context, nests related concepts, and articulates concepts that are inherently obvious to experts but often difficult for novices to grasp. Our BCF is also cross-referenced to highlight the connections between concepts. We have found our BCF to be a versatile tool for design, evaluation, and revision of course goals and materials. The approach is general and can be applied to the subject matter taught in courses at any institution. An up-to-date version of our BCF can be found online at http:/ /web.mit.edu/bioedgroup/HBCFmain.htm.

In the 2002-2003 academic year, D.G.H. designed a series of demonstrations paired with a problem or set of discussion questions that the students worked through in groups in recitation sections. The demonstrations consisted of the teaching assistant performing a DNA precipitation, simulating an Ames Test for mutagens, and running an agarose gel to separate the products of a restriction enzyme digest of DNA. The exercises were considered a success by the teaching assistants, but were limited by the amount of time in section and the restrictions of nonlaboratory space. They were also insufficient in scope for connecting different parts of the course. Therefore, equipped with the BCF as a guide, we designed an expanded set of activities to clarify particular key ideas that students found confusing. We put these activities together into a small-scale supplementary laboratory component for the Introductory Biology courses that clarified and connected ideas from different parts of the course.

\section{Course Design: The Importance of Both Hands-on and Minds-on Learning}

In the last decade or so, much research has been done on the teaching of physics that demonstrates a substantial gain in conceptual understanding of Newton's Laws when students participate in hands-on activities (Hake, 1998). This emphasis on active student involvement has spread to biology as well, and many reports such as the Boyer Report, Project 2061, and Bio2010 call for students to learn science by doing scientific research (American Association for the Advancement of Science, 1985, 1989; Boyer Commission, 1998; National Research Council [NRC], 2002).

At the same time, other educators have focused on teaching conceptual material through case- or problem-based techniques that "challenge students to 'learn to learn,' working cooperatively in groups to seek solutions to real world problems" (http://www.udel.edu/pbl/). These techniques focus on helping students learn concepts and develop critical-thinking skills.

We see the merit of both of these approaches, but feel that either one in the absence of the other may be limiting. We have heard anecdotal evidence that $\mathrm{K}-12$ teachers have found that simply providing hands-on activities without a strong minds-on component can lead to doing without understanding (Vandiver, personal communication). On the other hand, research demonstrates that students benefit from repeating cookbook labs for understanding (Sadler, 2004). We therefore designed our laboratory component to be a hybrid of these two approaches (Figure 1). The students spent roughly equivalent amounts of time performing minds-on and hands-on activities. As demonstrated in the Results section, the students valued both aspects of the course design.

\section{Course Objectives and the Role of the BCF}

In accordance with the course-design principles formulated by Wiggins and McTighe (2000) in Understanding by Design, we articulated our overall course objectives before planning the particulars. Our goals for the students' experiences in the laboratory are outlined in Table 1.

As can be seen in Table 1, some of the goals can be achieved by either hands-on or minds-on learning, but in order to achieve all six goals, the laboratory required a combination of hands-on and minds-on activities. Having students design (minds-on) and perform (hands-on) controlled experiments in a laboratory environment is an important first step in achieving goals I-IV. To achieve goal V, we provided the students with discussion materials (mindson) about several top-level concepts from the BCF in each session.

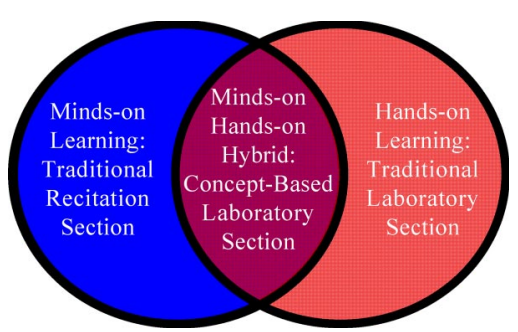

Figure 1. Concept-based laboratory section is a hybrid of minds-on and hands-on learning.

Table 1. Goals of the voluntary laboratory component

\begin{tabular}{lcc}
\hline Goals & Minds-on? & Hands-on? \\
\hline I. Make abstract concepts tangible. & No & Yes \\
II. Encourage learning in nonlecture format. & Yes & Yes \\
III. Expose the students to scientific method in action. & Yes & Yes \\
IV. Convey the excitement of performing experiments. & No & Yes \\
V. Make top-level concepts from the BCF explicit. & Yes & No \\
VI. Highlight connections between different topics in the course. & Yes & No \\
\hline
\end{tabular}

Achievement of some of the goals requires hands-on learning techniques, whereas achievement of others requires minds-on learning techniques. 
In designing each class session, we chose the relevant key concepts from the BCF and structured the session to address these concepts, their connections to each other, and their connection to material previously covered in the course. For example, in some sessions, we discussed how one cell repeatedly divides to become a colony, thereby highlighting the top-level concept "Cells are created from other cells."

The top-level concepts from our BCF that were used as guiding principles in designing the laboratory sessions are:

1. Biology is based on observational and experimental science.

2. At the molecular level, biology is based on threedimensional interactions of complementary surfaces.

3. The cell is the basic unit of life.

4. All cells share many processes/mechanisms.

6. Cells are created from other cells.

7. DNA is the source of heritable information in a cell.

8. A gene is the functional unit of heredity.

12. Proteins perform many varied functions in a cell.

13. Recombinant DNA technology allows scientists to manipulate the genetic composition of a cell.

(Khodor et al., 2004, Table 1, p. 115)

The numbering of the concepts is in accordance with our BCF as previously published. Numbering is for practical purposes and does not indicate relative importance.

To achieve goal VI, we designed most of the laboratory exercises so that they interwove to tell a story over multiple sessions and highlighted the connections between different topics within the course (minds-on). Although the sessions involved different topics, techniques, and questions, most involved investigating some aspect of the biosynthesis of the amino acid cysteine. Also, concepts from the BCF were featured in multiple sessions and in different combinations. This helped to transform seemingly discrete topics into more of a meshwork.

The goal of the laboratory component was not for students to achieve mastery of the laboratory techniques. MIT's Biology Department offers a separate semester-long sophomore laboratory course to achieve that goal. We describe the exercises further and provide a sample lesson plan in Materials and Methods below.

In this article, we describe the supplementary voluntary laboratory component as it was implemented in the fall semester of 2003, as well as concurrent and subsequent assessment of student attitudes and understanding. We discuss what we learned from both the experience of teaching the laboratory and the student assessment data, as well as the implications of these new understandings for future versions of such a laboratory component.

\section{MATERIALS AND METHODS}

\section{Laboratory Students and Schedule}

Three educationally equivalent versions of Introductory Biology are offered at MIT (7.012, 7.013, and 7.014; http:/ / web.mit.edu/7.01x/). The course in which this laboratory component was implemented, 7.012, was offered in the fall of 2003 and drew $\sim 475$ students. 7.012 covers biochemistry, genetics, molecular biology, gene regulation, recombinant DNA technology, immunology, cancer, the nervous system, and genomics. The course consists of 1-h lectures, delivered by professors three times per week, and 1-h small group recitation sections, led by graduate student teaching assistants twice per week. The faculty are assisted by a full-time, postdoctoral-level instructor who plans recitation section, problem set, and exam materials.

The students who participated in the laboratory component were volunteers and did not receive any credit for participation, but were encouraged to continue attending throughout the semester. The laboratory sessions described in this article met for $90 \mathrm{~min}$ on nine Mondays that were neither school holidays, nor the same week as a 7.012 exam. There were 21 students who participated in the laboratory exercises. These students were divided into two groups of 7 and 14, respectively; the first group met from 1:00-2:30 PM and the second group met from 3:00-4:30 PM.

\section{Laboratory Supplies and Lesson Plans}

An example of an abridged lesson plan is presented below.

\section{Abridged Lesson Plan for Session 3-Mutant Hunt}

The Main Idea: Geneticists use mutants to figure out how a biological system is supposed to work. First you identify a trait (phenotype) that you are interested in studying. Then you find an individual that does not have that trait. If you can then figure out which gene is different in your mutant, you have found the gene that is responsible for the trait.

1. How are genes responsible for traits?

In this set of experiments we are interested in studying the ability of the yeast Saccharomyces cerevisiae to make the amino acid cysteine.

2. Why would we be interested in cysteine biosynthesis?

3 . Why would we choose to study this process in yeast?

Stage 1: Making Mutants. Reminder: we did this stage the first week. A yeast culture was grown up overnight in SC liquid medium at $30^{\circ} \mathrm{C}$ with vigorous shaking.

I. Protocol to prepare cells for irradiation. The protocol includes the following question:

1. How do we decide how many colonies to plate?

II. Protocol for irradiation

III. Protocol for plating

Stage 2: Screening for Mutants. We are going to perform this step today. Yeast have been mutagenized and grown for 3 days on complete medium agar at $30^{\circ} \mathrm{C}$ as described in Stage 1.

1. What is in complete medium?

2. What is in minimal medium?

3. If you wanted to make media on which to grow a strain that was unable to synthesize cysteine, what would you need to put in it?

4. What medium could we use to screen for cysteine auxotrophs?

5. What is a selective condition?

6. Why don't we plate the mutagenized yeast directly on selective conditions?

7. How should we find the rare mutant yeast that cannot synthesize cysteine within the large collection of yeast colonies we have on the plates?

IV. Replica plating protocol. While an instructor demonstrates proper replica plating technique, discuss why the plates need to be properly marked and tapped lightly while on the replica plating block.

Stage 3: Identifying Mutants. We are going to perform this stage today with plates that are replica plates (replica plating done by instructors) of the yeast that were plated the first week of class.

1. When you "screen" the plates, how do you identify the mutants?

V. Mutant screening protocol 
2. If we find some colonies that grow on $\mathrm{CM}$ but not $\mathrm{MM}$, can we determine which amino acid they are unable to synthesize?

3. How might we figure this out?

\section{Thought Question}

Thought question for this lesson can be found in the Thought Question section of the Discussion.

For access to all our lesson plans and answer keys, please refer to our Web site at http:/ / web.mit.edu/bioedgroup/labsnapshot.htm. The sessions were titled: 1) DNA Isolation and Mutagenesis; 2) Biochemistry-Proteins; 3) Mutant Hunt; 4) Identifying Mutant Genes-Complementation; 5) Library Construction-Component Visualization by Agarose Gel Electrophoresis; 6) Complementation by Cloning. Gene Therapy. Genetic Diagnostic Assay; 7) Ames Test for Mutagens and Carcinogens; 8) Ames Test II; and 9) Pizza Party and Wrap-Up.

All of the supplies used are commercially available (e.g., SigmaAldrich, VWR, Carolina Biologicals, EUROSCARF), except for some of the strains of Saccharomyces cerevisiae and Salmonella typhimurium, references for which can be found on the lab component Web site.

\section{Laboratory Session Design}

In designing this laboratory component we sought to expand the number and complexity of concepts covered by the small set of demonstrations designed and implemented by D.G.H. for use in recitation sections and to create a set of experiments that highlighted the connection between areas of the course. We used the $\mathrm{BCF}$ as a guide to help determine which concepts to cover and designed the experiments to correspond to the order in which topics were introduced in lecture.

The idea of using the BCF to design our course is supported by previous educational research. A number of studies indicate that models of cognition and learning need to be at the center of course design and assessment processes (NRC, 2001, 2003). By using the hierarchical structure and cross-references in the $\mathrm{BCF}$, we sought to provide useful cognitive structures that would facilitate meaningful acquisition of knowledge by the students and confront any of their misconceptions head-on (Novak, 2002).

The learning environment of our laboratory component was designed to conform to NRC best-practice guidelines (NRC, 2000). First, it was learner-centered, in that it was designed to be continually adjusted by taking into account the "knowledge, skills, attitudes, and beliefs that learners bring to educational setting" (NRC, 2000 , p. 133). Second, the learning environment was knowledgecentered, in that each session's and the overall course content was designed to help students acquire knowledge in ways that "lead to understanding and subsequent transfer" (NRC, 2000, p. 136). Third, the environment was assessment-centered, in that informal formative assessments used throughout the course were designed to "provide opportunities for feedback and revision..." and were "congruent with [the] learning goals" (NRC, 2000, p. 140). And finally, the environment was community-centered, in that the course, with its focus on experimental data, was well suited to establish "social norms that value the search for the understanding and allow students (and teachers) the freedom to make mistakes in order to learn" (Brown and Campione, 1994; NRC, 2000, p. 145).

Each 90-min laboratory session was designed around several key ideas from the BCF and consisted of four main parts: discussion of the Thought Question from the previous laboratory session, discussion of the biological concepts related to that session's experiments, discussion of the techniques used in that session's experiments, and the performing of experiments.

The Thought Question for each laboratory session was designed to help students integrate the concepts illustrated by the experiment in that session by addressing a question that was superficially unrelated but conceptually similar to the topic that was explored. In some cases the question asked the students to explicitly connect a seemingly unrelated topic and the experiment from that session. In other cases, the connection was hidden. Each session began with a discussion of the Thought Question from the previous session. For a few examples and further explanation, please see the Discussion section.

The students were provided with a handout that contained a series of discussion questions for each session. Working through these questions as a group allowed the instructors to link the conceptual material that had been covered in lecture to both the BCF and the experiments that would be performed by the students. For example, in the "Mutant Hunt" session (see Laboratory Supplies and Lesson Plans, above, in Materials and Methods), this discussion period not only reviewed and reinforced the concept of genes being responsible for phenotypes (concepts 7-3, 8, 8-1, and 8-9 from the $\mathrm{BCF}$ ), but used this idea to help the students figure out why the technique of replica plating would allow one to detect and isolate mutants. This discussion period also provided the structure in which to clarify the technical details of the experiments. For example, the students needed to understand not only why you would transfer cells from the colonies from one plate to another, but also practical laboratory matters such as why it was necessary to align the plates, not press too hard, and label everything carefully.

In each laboratory session, students carried out experiments interspersed with the discussions outlined above. Much of the setup was performed by the instructors ahead of time. The instructors chose which parts to prepare and which parts should be performed by the students as explored in the Discussion section below, in order to maximize the amount of time that could be spent doing the "interesting" parts of the experiments.

Regardless of the time allotted per aspect of each session, we always structured the discussion segments of the class to make sure to emphasize, often repeatedly, the key concepts from the BCF that were central to each session. We believe that this organization is what makes our course distinct from the many other laboratory courses and, at least partially, accounts for our success in achieving our educational goals. See Results for more discussion on this.

\section{Course Assessment}

Both quantitative and qualitative assessment methods were used to evaluate the success of this laboratory component. Likert scale preand postsurveys were administered to the students who participated in the laboratory component to assess their attitudes toward the experience as a whole and the relative impact of each of its aspects. Quantitative data from these surveys can be seen in Tables 2 and 3. Interviews of students, both those who participated in the laboratory component and those who did not, were conducted in May 2004 (five months after the end of the course).

With the exception of the supplementary laboratory component, the nonlab students received the same instruction as the lab students (same lectures, recitation sections, problem sets, and exams). The nonlab students were chosen to each match a particular lab student with respect to final grade in the course. We acknowledge that this matching does not presuppose that we have matched for ability, motivation, knowledge, and the many other factors that contribute to a student's performance in a course because of the matching fallacy (Hopkins, 1969). However, we do feel that it was the best approximation available.

The interviews were conducted by a visiting professor, Brian White, who had previously been a postdoctoral instructor for the Introductory Biology courses. Therefore, Professor White was familiar with the way that Introductory Biology is taught at MIT but had not previously met the students. We felt that this would encourage the students to be honest in their critique of the laboratory component and avoid interviewer bias. The interviews were $\sim 30 \mathrm{~min}$ in length and consisted of questions about attitudes toward the course and biology in general. The students were also asked to make conceptual connections between different elements of the course. In addition, the laboratory students were asked questions about the laboratory exercises. The interviews were audiotaped and professionally tran- 
scribed. Qualitative data from these interviews can be seen in Appendix A. See Appendix B for complete list of interview questions.

\section{RESULTS}

\section{Novel Design}

As discussed in Materials and Methods, our course design focused on communicating central concepts from our BCF and used various tools to achieve that goal. We designed the sequence of class sessions into a story line focused on a particular gene/protein across species; emphasized not only key concepts from the BCF for each class session, but also the connections between these concepts and any concepts discussed in other sessions; and interlaced discussion of concepts and performance of key parts of the experiments. As discussed below, these uncommon features contributed to our success and distinguished the course from many other laboratory courses. We strongly believe that this approach to course design would be beneficial to any laboratory class, because it would help students create a conceptual framework for the subject material and relate experimental techniques to the concepts within the framework.

\section{Who Participated}

We recruited students for the laboratory component by advertising it to the whole Introductory Biology class. Thirty students volunteered to participate for the entire semester and receive no credit. We were only able to accommodate the schedules of 21 of those students. Of these, two students dropped out in the first $2 \mathrm{wk}$, but the remaining 19 students continued to attend most of the time.

Table 2. Attitude questions regarding the voluntary laboratory component of Introductory Biology

\begin{tabular}{|c|c|c|c|c|c|}
\hline \multirow[b]{2}{*}{ Question } & \multicolumn{2}{|c|}{ Presurvey $(\mathrm{n}=21)$} & \multicolumn{2}{|c|}{ Postsurvey $(\mathrm{n}=17)$} & \multirow{2}{*}{$\frac{\text { Comparison }}{p \text { value }}$} \\
\hline & Avg. & SD & Avg. & SD & \\
\hline \multicolumn{6}{|c|}{$\begin{array}{l}\text { Rate agreement with the statements below on a scale of } 1-5 \text { ( } 1 \text { meaning you disagree completely to } 5 \text { meaning that you agree } \\
\text { completely). }\end{array}$} \\
\hline 1. help me in my further studies at MIT. & 3.850 & 1.245 & 3.706 & 1.312 & 0.9473 \\
\hline 2. help me in my future career. & 3.500 & 1.047 & 2.941 & 1.391 & 0.4220 \\
\hline $\begin{array}{l}\text { 3. help me better understand science-related } \\
\text { issues when I vote. }\end{array}$ & 2.900 & 1.194 & 3.059 & 1.391 & 0.4631 \\
\hline $\begin{array}{l}\text { 4. help me critically evaluate science coverage in } \\
\text { the media. }\end{array}$ & 3.000 & 1.222 & 3.176 & 1.331 & 0.3674 \\
\hline 5. improve my grade in 7.012 & 3.100 & 1.232 & 4.118 & 0.928 & $0.0058^{*}$ \\
\hline $\begin{array}{l}\text { 6. improve my understanding of the material } \\
\text { covered in } 7.012 \text {. }\end{array}$ & 4.300 & 1.081 & 4.471 & 0.800 & 0.1986 \\
\hline 7. improve my retention of the material in 7.012 . & 4.300 & 1.098 & 4.353 & 0.786 & 0.2914 \\
\hline $\begin{array}{l}\text { 8. help connect the concepts from different units } \\
\text { in } 7.012 \text {. }\end{array}$ & 4.350 & 1.103 & 4.412 & 0.712 & 0.3093 \\
\hline $\begin{array}{l}\text { 9. help ground concepts in the reality of } \\
\text { experiments. }\end{array}$ & 4.650 & 1.131 & 4.294 & 0.920 & 0.8143 \\
\hline
\end{tabular}

Table 3. Student attitudes toward relative importance/value of the different components of the voluntary laboratory component

\begin{tabular}{lllll} 
& & & & Postsurvey $(\mathrm{n}=17)$ \\
\cline { 2 - 3 } Question & Avg. & & Comparison & $p$ value \\
\hline
\end{tabular}

Rate the contribution of the activities listed below to improving your understanding of the material covered in 7.012 on a scale of $1-10$ (with 1 being none and 10 being highly significant).

\begin{tabular}{|c|c|c|c|c|}
\hline A. Performing experiments & 7.353 & 1.998 & $\begin{array}{l}\text { to } B \\
\text { to } C \\
\text { to } D\end{array}$ & $\begin{array}{l}0.033^{*} \\
0.859 \\
0.901\end{array}$ \\
\hline B. In-class discussion of concepts & 8.118 & 1.867 & to $C$ & 0.069 \\
\hline C. In-class discussion of experimental techniques & 7.412 & 2.320 & to $\mathrm{D}$ & 0.848 \\
\hline D. Spending more time with 7.012 staff & 7.294 & 2.616 & & \\
\hline
\end{tabular}

Posttest averages, SDs, and two-tailed, paired $t$ test results.

* Below the critical $p$ value of 0.05 . 
A diverse mix of students signed up including freshmen, juniors, seniors, and graduate students from other departments. This alleviated our concern that the only students interested in participating would be freshmen interested in pursuing a major in biology or a biology-related field or premed students. Only 6 of the 21 students in the laboratory had declared, intended to declare, or considered declaring biology as a major.

Students in the laboratory had a wide range of motivations for taking the course. More than a quarter identified themselves as hands-on learners or as interested in learning in nonlecture format; most were looking for laboratory experience either as preparation for a laboratory course, undergraduate or graduate research, or to tie course concepts to the reality of experiments; and a number believed that the laboratory would help them understand and retain concepts or other material from lectures.

Comparing final grades of the laboratory students with those of the class as a whole shows that the students in the lab as a group received slightly higher grades, with $31.6 \%$ of the lab students getting A's (vs. $26.2 \%$ for the class as a whole) and $15.8 \%$ getting $\mathrm{A}-$ 's (vs. 10.3\%). Although some students performed better than average, it is important to point out that there was still a wide spread of student grades: $26.3 \%$ of the lab students received a B (vs. $27.5 \%$ of the class as a whole), $15.8 \%$ received a B- (vs. $8.5 \%$ ), and $10.3 \%$ received a $\mathrm{C}-$ (vs. $3.3 \%$ of the class as a whole receiving $C^{\prime}$ s and $15.7 \%$ receiving $C^{-}$'s). It is difficult to draw any firm conclusions because the laboratory group was self-selected for motivated students, and the numbers in the laboratory group are so small that a change in just a few students' grades would have a large impact on percentage numbers.

The following anecdotes illustrate the range of students in the laboratory. One student had a number of learning disabilities and had started and dropped the course at least twice before Fall semester of 2003 when she also signed up for our laboratory. Although her final grade was a $\mathrm{C}-$, she was happy to have completed and passed the course. In addition, she felt that the lab was beneficial to her understanding of course material. On her exit survey she wrote: "The labs tied nicely to the material being covered in lectures, the problem sets and most importantly, the exams. The material in 7.012 builds onto each other and the labs did the same thing. The thought questions were a great way to recall the previous lab and tie it into the new lab. [Instructors]. . . took the time to make us understand what we were doing, by asking questions and making us recall previous concepts. .."

A second student was a graduate student studying Computational Biology. He signed up for the laboratory component because he believed the laboratory experience would benefit his graduate studies. When we discovered that he was not registered for the course, he explained that he was under a units cap and had to audit the class. Thus, even though he was not receiving credit or a grade for the course, this student attended the laboratory sessions regularly throughout the semester.

A third student (referred to as student $G$ in Appendix A) was a senior who also received a $\mathrm{C}-$ in the course. However, in his follow-up interview he displayed a higher level of understanding of the concepts than his grade would indicate. In addition, this student asked us how he, as a person who is about to graduate and enter the work force in an unrelated field, could go about trying to keep learning about biology.

We found that having a heterogeneous group of students was a benefit to the group. On more than one occasion, we observed that the questions posed by the less knowledgeable students led to a discussion that illuminated important concepts not only for the student who originally posed the question, but also for many of the more advanced students.

\section{Students Were Highly Satisfied with the Experience}

To determine student attitudes and possible changes in attitudes about potential benefits of participating in the laboratory component, we administered surveys to the students before the first session and at the end of the term. These surveys consisted of Likert scale questions. The data are displayed in Table 2. We draw two major conclusions from this data: one, the students had high expectations for the laboratory component and two, in all cases their expectations were met or exceeded.

Interestingly, there was a statistically significant $(p=$ 0.0058 ) increase in student assessment of whether participating in the lab sessions would improve their grades in the accompanying lecture course (Q.5). As the Bonferroni inequality would suggest, the multiple $t$ tests present the problem of a possible overall inflated $\alpha$. However, given the exploratory nature of the study, the $p$ of 0.0058 for Q.5 is sufficiently low to permit hypothesizing about the implication of the value. It is also worth pointing out that the laboratory component received very high marks (4.294 or higher out of 5) with respect to helping students to understand concepts (Q.6), retain concepts (Q.7), connect concepts (Q.8), and ground concepts in the reality of experiments (Q.9).

Perhaps the best indicator that the students found participating in the laboratory component worthwhile is that even though it was voluntary, the vast majority of students attended the sessions regularly and continued to do so throughout the semester. Some students admitted in their surveys that when many demands were being placed on their time, they stopped attending lectures of some of their courses but continued to attend our voluntary lab.

\section{Assessment of Major Goals}

In the interviews, conducted five months after the end of the course, students who participated in the voluntary laboratory component were asked a variety of questions (Appendix B), including the following questions:

1. How do you feel about the lab in general?

2. Were there some experiments that were particularly memorable? Why did you do them?

3. Were there some experiments that you particularly liked?

4. Were there some experiments that you think were not worth doing?

Below we evaluate the laboratory component with respect to attainment of the six goals outlined in the Introduction. Appendix A contains excerpts of student responses to the four questions above, sorted as they relate to the six goals. It is noteworthy 
that the students made these comments without being directly prompted to evaluate our attainment of the goals.

I. Make Abstract Concepts Tangible, II. Encourage Learning in Nonlecture Format, III. Expose the Students to Scientific Method in Action, and IV. Convey the Excitement of Performing Experiments. All four of these goals were met by bringing the students into a laboratory environment where they participated in discussions and performed interesting and well-controlled experiments.

Some of the abstract concepts covered in the lecture portion of the course became tangible realities for the students when they were able to see and touch many of the reagent and apparatuses discussed in lecture. The students also experienced the excitement of performing experiments when they isolated their own DNA and "cured" yeast that "suffered" from cysteine auxotrophy.

All of the learning in the laboratory sessions consisted of either discussion (minds-on) or experimentation (hands-on). Because there were no lectures and the students felt that they learned a great deal, we feel that the laboratory component met the goal of encouraging learning in a nonlecture format.

During the discussions and performing of experiments the students were exposed to the scientific method in action. The students learned to always design and implement controls and to use these controls when interpreting the results of their experiments. The students were also exposed to the reality of experimental failure-some experiments did not work for some students, and one partially failed to work altogether as described in the Discussion. We found that discussing why experiments failed without attaching educational consequences to this failure was a very effective educational tool that contributed to creating an educational community in the laboratory (as defined in NRC, 2000).

Student thoughts on the aspects of the course related to these goals can be found in Appendix A.

V. Make Top-Level Concepts from the BCF Explicit and VI. Highlight Connections between Different Topics in the Course. Unlike the other four goals, which can be achieved through a well-designed and implemented laboratory course (hands-on), the related goals of making top-level concepts from the BCF explicit and highlighting the connections between different topics in the course required a second type of learning (minds-on).

We wished to investigate whether the students gain an appreciation for the connectedness of different topics in the course. Therefore, during the interviews they were asked to explain "Why does the course include both biochemistry and genetics?" Answers varied widely and so the interviewer used the prompt "Is there a connection between biochemistry and genetics?" to try to elicit the concept that genes encode proteins. If this was unsuccessful, the interviewer used a second prompt: "How would you explain the genetic terms gene and allele using biochemical terms?"

Students' answers were evaluated according to the following criteria: A) Did they acknowledge a connection? B) Did they realize that the biochemistry and genetics were occurring in the same cell? C) Did they explain that biochemistry and genetics were connected via genes encoding proteins? D) Did they explain that genes encode proteins that then carry out functions in the cell, thereby generating a phenotype? The grading of these responses was performed by a course instructor who knew neither the students' names nor which students had participated in the laboratory component.

Criterion A: four of the eight nonlab students thought that biochemistry and genetics were in the same course because they are connected. Two of the remaining four thought there might be a connection, and two saw no connection at all. In contrast, all seven of the laboratory students thought that the topics were connected. Criterion B: only four of the eight nonlab students demonstrated an understanding that biochemical and genetic processes occur in the same cell, whereas all seven lab students demonstrated this understanding. Criterion C: six of eight nonlab students explained that the connection between biochemistry and genetics was that genes encode proteins, whereas six of seven lab students gave this explanation and the seventh hinted at it, but did not give a complete answer. Criterion D: only four students took their explanation to the point of discussing that genes encode proteins and proteins function to create phenotypes. Three of these students participated in the lab and one did not.

Because the sample size is so small and the question was so open ended, it is difficult to draw any statistically significant conclusions from the data. However, there is a striking and consistent trend demonstrating that the students who participated in the laboratory component were better able to see the connections and articulate the top-level ideas that were inherent in a discussion of why the course might include both biochemistry and genetics than students who did not participate in the lab component.

We conclude the students who participated in the class had a better comprehension of top-level concepts, because in order for the students to explain the connection between the principles of biochemistry and genetics they must understand top-level concepts 2, 7, 8, and 12 (see Introduction). If the students did not understand these concepts, they would have been unable to link biochemistry and genetics through the central dogma of molecular biology.

\section{Relative Contributions of Four Aspects of Each Laboratory Session}

Based on our initial small-scale assessments, it seems that students who participated in the laboratory component demonstrate some improvement in their understanding and attitudes. However, in principle it is possible that such gains would result from any intervention, rather than from the particulars of our laboratory component. To try to determine what led to the student improvement, students were asked to rate the contribution of the four aspects of the laboratory component: performing experiments, in-class discussion of concepts, in-class discussion of experimental techniques, and spending more time with 7.012 staff. The results are presented in Table 3. As discussed previously, multiple $t$ tests present the problem of possible inflation of the overall $\alpha$. In that the sample size is small and that the study is exploratory in scope, review of $t$ test results is instructive as long as one remains mindful of the Bonferroni inequality.

On average, students ranked discussion of concepts as the most important aspect of the class. Further, when the relative contributions of the four aspects are compared pair-wise using the two-tailed $t$ test, there is a statistically significant 
( $p=0.033$ ) difference between the student-perceived value of discussing the concepts and actually performing the experiments. In the other two pair-wise tests involving discussion of concepts, the concept aspect of the course rated consistently higher, although not below the $p=0.05$ statistically significant cutoff. Because several $t$ tests were run, the Bonferroni inequality applies. However, the data suggest that class discussion played a leading role. Given the exploratory nature of the study and small sample size, further study is necessary to verify this claim. We, therefore, conclude that discussion of concepts was a key element of the course, from the students' perspective.

This assessment is of particular interest to the instructors, since the original idea of designing this course was to focus on the concepts in the context of experiments. We, therefore, feel that this concept-centered blending of the minds-on aspect of discussion and the hands-on aspect of performing experiments succeeded, at least in impressing upon the students the central role that understanding the concepts plays in modern biology. In the interview one student (student A in Appendix A) talked about the importance of concepts in the course this way: "And the fact that we talked about things and I did the experiments instead of just doing the experiments was, I think, a really good thing. . . . if you don't understand the background, and you just do the procedure, it's going to mean nothing." Another student (student E in Appendix A) pointed out the need for blending approaches when she said "I think that just being able to do what you're learning about [in class] grounds it in reality." These quotes highlight the combination of hands-on and minds-on activities as an effective mechanism for teaching biology.

\section{DISCUSSION}

On the basis of the surveys and student interviews, we conclude that the laboratory component was a success on two levels. One, the students gave it very high marks and continued to attend the sessions despite the fact that this was completely voluntary and they would receive no credit for participation. Two, the students who participated in the laboratory component are better able to articulate key concepts from the BCF and identify the connections between them.

Our voluntary laboratory sessions bore many resemblances to other laboratory courses. However, there were five key features that we believe contributed to its success. Here, we report and discuss an example of the efficacy of each feature. Materials and Methods includes an abbreviated example of one of our lesson plans. Some particular examples in the discussion below come from the lesson plan in Materials and Methods.

\section{Use of a Story Line}

In agreement with the NRC report, How People Learn (2000), we feel that reviewing important concepts as they arise within the story line of investigating cysteine biosynthesis should enhance learning and retention of concepts. We chose to use the yeast CYS4 gene and protein as the lead player in a story that continued over many sessions, because cys4 null mutants have easily identifiable phenotypes in yeast and humans
(http://www.incyte.com/proteome/YPD/CYS4.html; Kruger and Cox, 1994; Kabil et al., 2001). In addition, access to a mutant protein with characterized changes in size and activity (Jhee et al., 2000) and the existence of a yeast assay for the functionality of various human alleles of CBS (human analog of CYS4; Kruger and Cox, 1995; Shan et al., 2001) made cysteine biosynthesis a versatile choice for the story line.

When using a story line, ideas are introduced "just in time," helping the students appreciate the applicability of the new knowledge and make sense of it. In addition, when instructors repeat previously covered material in a slightly different context, it should enhance students' abilities to transfer that knowledge to a new situation (NRC, 2000; Anderson et al., 1996). For example, during a class session students were initially stumped when asked to explain a genetic phenomenon in biochemical terms. However, upon consideration of the cysteine auxotrophs they had isolated and the mutant protein they had run on a gel, the students were able to appreciate and articulate why and how every genetic phenomenon must ultimately have a biochemical explanation. The story line helped the students make connections between concepts from different units of the course. Student comments on their perceived benefit of the story line are listed in Appendix A. Others researchers have also documented the positive effect of theme-based curricula on the development of student skills and attitudes (Norton et al., 1997).

\section{Emphasis on Discussing the Concepts}

Compared with learning environments that stress memorization, a learning environment in which the students' understanding of relevant concepts is explored and challenged improves learning, retention, and transfer of those concepts (NRC, 2000). Discussing concepts also allows us to uncover connections between various concepts and topics in the course. For example, discussing why we UV irradiate yeast and plate them on complete media as the first step in an auxotrophy screen allowed us to explicitly articulate how clonal colony formation is based on the concepts of DNA being the genetic material in a cell and cells being produced from other cells. Discussion of the concepts behind the experiments also allowed for multiple opportunities for informal formative assessment. In addition, research has shown that class formats combining concept discussion with experiments (minds-on hands-on hybrid) seems to increase student appreciation for the nature of the subject as well as the connected nature of the concepts in it (Laws, 1991).

\section{Benefits of Discussing the Techniques}

We perceived great value in discussing the concepts behind the actual experimental techniques involved. Research has shown that approaches such as this aid in improving transfer (Anderson et al., 1996; NRC, 2000) as well as concept retention, and the understanding of connections between concepts (NRC, 2000). For example, cloning by complementation and the use of different media for screening colonies were assessed on a midterm exam after being discussed both in the lecture and recitation section portion of the class. The logic of the exam question (which we did not write) followed a flow similar to our planned laboratory session on the topic. Many laboratory students felt that if only they had 
that laboratory session before the exam, it would have helped them master the concepts and they would have been better able to answer the exam question. We think that this approach of discussing the concepts behind laboratory techniques also helps remove student apprehension about "doing the lab right" as discussed below.

\section{Student Performance of Key Parts of the Experiments}

We did not have enough time in each laboratory session to have students perform the experiments in their entirety. Our solution was to focus student attention on performing only the most interesting, fun, or instructive portions of the experiment. For example, students did not pour agar plates, but they did plate the yeast, identify and pick potential mutant colonies, and streak them onto new plates.

However, we made sure to discuss the unperformed aspects of the experiment. Students did not pour their own denaturing protein gels, but we did discuss what such a gel consists of, how and why it works, and what else is needed for electrophoresis to work. The goal of this design, which was well received by students, was to ensure understanding of the concepts behind the laboratory techniques and to promote understanding of the connections between various concepts behind the techniques. One student (student F in Appendix A) commented in her interview that she "didn't like [her] previous labs because [she] was nervous about not doing it right, [she] was worried about finishing." In this laboratory class, "[the instructors] do all of the crunch work for you" and thereby eliminate this nervousness about time and mistakes. The concept of limited laboratory exposure targeted to improve student understanding is not new. Since 1992, CityLab at Boston University, and now their MobileLab, have had great results serving tens of thousands of high school students with short discovery-based laboratories (Franzblau et al., 2001).

\section{Thought Questions}

As described in Materials and Methods, we ended each laboratory session by posing a Thought Question that was designed to help the students integrate the concepts illustrated by the experiments in that session, and a discussion of the students' answers was used as the start of the next session.

Below are Thought Questions for laboratory sessions 3 and 4 , in which students identify mutant yeast that are unable to synthesize cysteine (Session \#3) and then mate yeast strains to determine which strains harbored mutations in the same complementation group (Session \#4).

Session \#3: In 1908 a physician in London named Archibald Garrod had some new patients with an unusual condition: when their urine came into contact with air it turned black. Compare his quandary to the lab we did today.

i) In both cases (our lab and Dr Garrod's clinic) who or what

Is the wildtype phenotype?

Is the assay?

Is the mutant? ii) By calling something or someone a mutant what assumption have we made?

iii) What else would you want to know about Dr Garrod's patients to determine if this assumption is correct?

Session \#4: Two patients who both suffer from the disease in which their urine turns black upon contacting air meet in Dr. Garrod's office. They fall in love, get married, and have a child. The child does not have the black urine disease. What are the possible explanations?

The first of these questions asks students to draw direct parallels between the experiment they performed and a classic study (Garrod, 1902). In the next question, the link to the experiment performed by the students is not as explicit, but continues with the experimental scenario. However, discussing the actual results of the complementation experiment led to the formulation of an unanticipated answer to the Thought Question. Because there was a contaminant in one of the yeast strains used in the complementation assay, the controls gave conflicting results. On discussing how possible contamination confounded our interpretation of results, one of the students thought back to our discussion of the Thought Question where parents who both had black urine disease had a child who did not have the disease and exclaimed "Maybe Mrs. Black Urine was unfaithful!" This demonstrates not only an ability to understand the experiment and its interpretation, but to apply this understanding to new situations.

As illustrated by the above example, Thought Questions provided continuity from one session to the next, allowed students an additional chance to learn and retain the concepts covered in the previous week's laboratory, to see how that knowledge can be transferred and applied to a new context, to make connections between various concepts from the previous labs, and possibly to build a bridge to the concepts in the new lab, all of which is consistent with contributing to improved student performance (NRC, 2000). In addition, Thought Questions allowed us consistent opportunities to practice formative assessment and to provide students with feedback and additional clarification of the concepts from previous sessions, which is critical to student success (NRC, 2001, 2003). Finally, because these questions mostly described real-world situations they created an opportunity for students to notice and appreciate the role biology plays in their world.

\section{Transferability}

Interestingly, time spent with the course staff received the lowest average value of the four elements considered as contributing to student success in the course (Table 3). These results are encouraging to us because they indicate that it was the course design, using the principles of the BCF as a guide, rather than the personalities of the instructors that contributed to student success. Although initial course design, individual session design, procurement of materials, and first-time experiment preparation took a significant investment of our time and energy, the lesson plans are now available to all who are interested in implementing our laboratory component at their institutions (http://web.mit.edu/ 
bioedgroup/labsnapshot.htm). The data above indicate that using this laboratory component would be beneficial in any environment where a focus on concepts is desired.

We feel that many of the laboratory sessions we have designed and tested are highly transferable because the topics chosen would likely be found in any undergraduate Introductory Biology class. Ultimately we feel that our approach is highly transferable because most large lecture classes already have a small learning environment component in the form of a lab or recitation section. We argue that these sessions can be used very effectively if they are modified to become a hybrid of both hands-on and minds-on activities guided by a concept framework.

\section{ACKNOWLEDGMENTS}

We thank Brian White for conducting the interviews, Michelle Mischke for scoring the answers to the question about the connection between biochemistry and genetics, and Kimberly Tanner for helping us to think about how to analyze our work and construct the manuscript. This work was funded by a Howard Hughes Medical Institute Professorship awarded to G.C.W.

\section{REFERENCES}

American Association for the Advancement of Science (1985). Project 2061, Benchmarks for Science Literacy. http:/ /www.project2061.org/ tools/benchol/bolframe.html/ (accessed 19 January 2006).

American Association for the Advancement of Science (1989). Project 2061, Science for all Americans. http://www.project2061.org/tools/ sfaaol/sfaatoc.htm/ (accessed 20 January 2006).

American Institutes for Research (2003). High Time for High School Reform: Early Findings from the Evaluation of the National School District and Network Grants Program. http://www.gatesfoundation. org / nr / downloads / ed / smallschools / Small_schools_eval_2003.pdf (accessed 20 January 2006).

Anderson, J. R., Reder, L. M., Simon, H. A. (1996). Situated learning and education. Educ. Res. 25, 5-11.

Boyer Commission (1998). Reinventing Undergraduate Education: A Blueprint for America's Research Universities. http:// naples.cc.sunysb.edu/Pres/boyer.nsf/ (accessed 20 January 2006).

Brown, A. L., and Campione, J. C. (1994). Guided discovery in a community of learners. In: Classroom Lessons: Integrating Cognitive Theory and Classroom Practice, ed. K. McGilly, Cambridge, MA: MIT Press, Chapter 9, 229-270.

Cotton, K. (2000). The Schooling Practices That Matter Most. Alexandria, VA: Association for Supervision and Curriculum Development and Portland, OR: Northwest Regional Educational Laboratory.

Franzblau, C., Derosa, D., and Phillips, C. (2001). Science on wheels. Sci.Teach. 68, 25-27.

Garrod, A. E. (1902). The incidence of alkaptonuria: a study in chemical individuality. Lancet 2, 1616-1620.

Hake, R. (1998). Interactive engagement versus traditional methods: a six-thousand-student survey of mechanics test data for introductory physics courses. Am. J. Phys. 66, 64-74.

Holland, N. E. (2002). Small Schools Making Big Changes: The Importance of Professional Communities in School Reform. Chicago, IL: Consortium on Chicago School Research, University of Chicago.
Hopkins, K. D. (1969). Regression and the matching fallacy in quasiexperimental research J. Special Ed. 3(4), 329-336.

Jhee, K. H., McPhie, P., and Miles, E. W. (2000). Domain architecture of the heme-independent yeast cystathionine beta-synthase provides insights into mechanisms of catalysis and regulation. Biochemistry 39, 10548-10556.

Jobs for the Future, Kellogg Foundation (2002). Learning Outside the Lines: Six Innovative Programs That Reach Youth. http://www. wkkf.org/Pubs/YouthED/Pub3728.pdf/ (accessed 20 January 2006).

Kabil, O., Toaka, S., LoBrutto, R., Shoemaker, R., and Banerjee, R. (2001). Pyridoxal phosphate binding sites are similar in human heme-dependent and yeast heme-independent cystathionine betasynthases. Evidence from 31P NMR and pulsed EPR spectroscopy that heme and PLP cofactors are not proximal in the human enzyme. J. Biol. Chem. 276, 19350-19355.

Khodor, J., Halme, D. G., and Walker, G. C. (2004). A hierarchical biology concept inventory: a tool for course design, assessment, and revision. Cell Biol. Educ. 3, 111-127.

Kruger, W. D., and Cox, D. R. (1994). A yeast system for expression of human cystathionine beta-synthase: structural and functional conservation of the human and yeast genes. Proc. Natl. Acad. Sci. USA 91, 6614-6618.

Kruger, W. D., and Cox, D. R. (1995). A yeast assay for functional detection of mutations in the human cystathionine beta-synthase gene. Hum. Mol. Genet. 4, 1155-1161.

Laws, P. (1991). Workshop physics. Change 23, 20-27.

National Research Council (2000). How People Learn: Brain, Mind, Experience, and School, expanded edition. ed. J. D. Bransford, A. L. Brown, and R. R. Cocking, Washington, DC: National Academy Press. http://books.nap.edu/catalog/9853.html (accessed 20 January 2006).

National Research Council (2001). Knowing What Students Know: The Science and Design of Educational Assessment, ed. J. W. Pellegrino, N. Chudowsky, and R. Glaser, Washington, DC: National Academy Press. http://books.nap.edu/catalog/10019.html (accessed 20 January 2006).

National Research Council (2002). Bio 2010, Transforming Undergraduate Education for Future Research Scientists, ed. L. Stryer, Washington, DC: National Academy Press. http://nap.edu/catalog/10497.html (accessed 20 January 2006).

National Research Council (2003). Evaluating and Improving Undergraduate Teaching in Science, Technology, Engineering, and Mathematics, ed. M. A. Fox and N. Hackerman, Washington, DC: National Academy Press. http://books.nap.edu/catalog/ 10024.html (accessed 20 January 2006).

Norton, C. G., Gildensoph, L. H., Phillips, M. M., Wygal, D. D., Olson, K. H., Pelligrini, J. J., and Tweeten, K. A. (1997). Reinvigorating introductory biology: a theme-based, investigative approach to teaching biology majors. J. College Sci. Teaching 27, 121-126.

Novak, J. D. (2002). Meaningful learning: the essential factor for conceptual change in limited or inappropriate propositional hierarchies leading to empowerment of learners. Sci. Educ. 86, 548-571.

Sadler, P. M. (2004). Factors Influencing College Science Success. A Briefing on a National Study of Undergraduates in Introductory College Science Courses. National Academy of Sciences Workshop Investigating Introductory Science Courses in the Undergraduate Context: A Systems Approach, June 22-23, 2004.

Shan, X., Dunbrack, R. L., Jr., Christopher, S. A., and Kruger, W. D. (2001). Mutations in the regulatory domain of cystathionine betasynthase can functionally suppress patient-derived mutations in cis. Hum. Mol. Genet. 10, 635-643.

Wiggins, G., and McTighe, J. (2000). Understanding by Design. Upper Saddle River, NJ: Merrill Education/Prentice Hall. 


\section{Appendix A \\ EXCERPTS FROM INTERVIEWS OF STUDENTS PERFORMED FIVE MONTHS AFTER THE END OF THEIR PARTICIPATION IN THE VOLUNTARY LABORATORY COMPONENT OF INTRODUCTORY BIOLOGY}

Interviews were performed by a visiting professor who was familiar with the course material but had no previous contact with the students. A full list of interview questions can be found in Appendix B.

\section{Make Abstract Concepts Tangible}

Lab student A: It's very easy to try to say in the lecture that UV radiation causes mutagenesis. When you actually go in a lab and you look and you say, okay, this is the plate originally, this is the plate after I've subjected it to UV radiation. Wow it does not look the same.

Lab student F: [I]t was kind of like the picture just sink in my head and then like, sometimes when I was sitting for the exam, in the exam, [the picture] would just come.

Lab student C: [I]t was interesting to see ... you can actually change cells just by inserting something in them.

Lab student E: I just think being able to do what you are learning about grounds it in reality.

Lab student B: It's interesting to see how stuff is actually done. You know, like you read about in all these magazines and newspapers.

\section{Encourage Learning in a Nonlecture Format}

Lab student A: [I]t was a chance to clarify in a smaller environment, where you could actually see and understand why.

Lab student E: I think it's a lot easier to understand what's happening after you actually do the experiment.

\section{Expose Students to Scientific Method in Action}

Lab student C: You can't expect to be perfect all the time, and no one's going to have it work out all the time, and you've just got to look for what went wrong and figure[it] out.

\section{Convey the Excitement of Performing Experiments}

Lab student G: I think that whole atmosphere that it-I know this sounds as hokey as it sounds-but biology as a science of discovery.

Lab student A: [I]t's really, really cool to see your DNA in this little tube.

Lab student E: I particularly liked to isolate your own DNA. I just thought that was fun.

Lab student B: [I]t was interesting. It wasn't mind blowing. but it was cool.

Lab student G: Yeah, so that was cool because you have a little vial of [DNA].

\section{Students Recognizing and Valuing the Story Line:}

Lab student A: I think that it was very helpful because they had this sort of constant line that they were looking at and they were trying to attach different subjects on each point, which was a lot easier when you had something to attach them to.

Lab student F: What made them memorable? The reason I remember those [experiments] is because we had talked at the end about how what we were looking at was like a whole system. That's why we used cysteine the whole time.

\section{Appendix B \\ THE INTERVIEW QUESTIONS}

Questions labeled with an asterisk were asked only of students who participated in the laboratory component. All students were asked the unlabeled questions.

1. Why did you take 7.012?

2. In what ways did the course meet your expectations?

3 . In what ways did the course not meet your expectations?

4. What in the class engendered good attitudes about biology (as a science or a thing to study)?

5. What in the course turned you off to biology (as a science or a thing to study)?

6. Were there any take home messages in the class?

$7^{*}$. How did you feel about the lab?

$8^{*}$. Were there some experiments that were particularly memorable? Why did you do them?

$9^{*}$. Were there some experiments that you particularly liked?
$10^{*}$. Were there some experiments that you don't think were worth doing?

$11^{*}$. What in the lab engendered good attitudes about biology?

$12^{*}$. What in the lab engendered bad attitudes about biology?

$13^{*}$. What is the relationship between the lab and the class?

14. Why does the class include both biochemistry and genetics?

15. What do you think it means to be a biologist? What do they do all day?

Follow-up questions to parts of the survey:

16. Cold virus experiment - Can the virus be spread through the air?

17. Cold virus experiment - Is spreading through the air the most efficient way?

18. What ideas/concepts from the course come to mind when reading the AIDS article? 